\title{
Detecting the effects of neuroprotection in living cells
}

\begin{abstract}
This paper describes experiments in cell systems that have helped clarify intracellular mechanisms leading to apoptosis. Using the cellular systems described (rat retinal whole mount, rat retinal cell line E1A-NR3, and rat neuronal cell line NG 108-15), it has been possible to demonstrate that intracellular pH change may be the mechanism through which carbonic anhydrases modulate vasodilation and act on retinal blood flow. Intracellular $\mathrm{pH}$ can also be used to monitor intracellular changes that precede and occur during apoptosis. The findings also show the potential significance of advanced glycation end products (AGEs) in the glaucomatous process, and the potential for brimonidine and memantine to rescue neuroretinal cells from AGE-induced retinal damage.
\end{abstract} Eye (2007) 21, S38-S41; doi:10.1038/sj.eye.6702887

Keywords: neuroprotection; retinal cell line; whole mount; brimonidine; memantine; cell stress

Department of Anatomy, Medical Faculty, Technical University of Dresden, Dresden, Germany

\section{Correspondence:}

RHW Funk,

Department of Anatomy, Medical Faculty, Technical University of Dresden, Germany Tel: + 493514586110 . E-mail: richard.funk@ tu-dresden.de

\section{Introduction}

This paper describes two methods involving living retinal cells, whole-mount ex vivo retina preparations and retinal neural cell cultures, to study the effects of neuroprotective agents.

Using these approaches, it has been possible to elucidate the finer details of the mechanisms involved in the neuroprotective processes, such as changes in intracellular $\mathrm{pH}$, and the ways in which some drugs may benefit the patient.

Intracellular $\mathrm{pH}$ as an indicator of cell stress and apoptosis

Animal models are useful for studying the mechanisms of agents that are potentially involved in the protection of glaucomatous optic nerve damage. In the ex vivo rat retina preparation, computer imaging with a high resolution and a deconvolution system was used to visualize the sections of the retina containing living cells. This method can be used to see changes in vessel diameter and has potential for use both in vivo or ex vivo.

We used this model to compare dorzolamide and acetazolamide, two blockers of carbonic anhydrase (CA) that may modulate regional blood flow by mediating changes in extra- and intracellular $\mathrm{pH} .{ }^{1}$ At that time, it was unclear whether blockers of $\mathrm{CA}$ really changed the $\mathrm{pH}$ near retinal capillaries and also how changes in the local $\mathrm{pH}$ affected the capillary tone in situ.

The rat retinas were observed in a chamber for electron light microscopy or were fixed for immunohistochemistry. Changes in capillary diameter were measured, and intracellular $\mathrm{pH}$ was analysed in the whole mounts by ratio imaging of the $\mathrm{pH}$ using the special dye BCECF-AM (2,7-bis-(2-carboxyethyl)-5-(and -6)carboxyfluorescein acetoxymethyl ester) and the extracellular $\mathrm{pH}$ using nonesterized BCECF (2,7-bis-(2-carboxyethyl)-5-(and -6)carboxyfluorescein).

Acetazolamide and dorzolamide showed statistically significant vasoactive effects in retinal capillaries. Vasodilation increased by up to $105 \%$ of that in control capillaries after 5, 10, and $15 \mathrm{~min}$. CA inhibitors were able to induce intracellular alkalization in retinal cells. After addition of dorzolamide or acetazolamide, there was a decrease of extracellular $\mathrm{pH}$, but an increase in intracellular $\mathrm{pH}$ concomitant with diameter changes. Thus, it may be concluded that CA inhibitors can relax retinal vessel capillaries concomitant with $\mathrm{pH}$ changes and might improve retinal blood supply.

Monitoring of intracellular $\mathrm{pH}$ can allow cell stresses and their cumulative effect on cell apoptosis to be determined. ${ }^{2}$ A dye that is frequently used to indicate the mitochondrial transmembrane potential is $5,5^{\prime}, 6,6^{\prime}$-tetrachloro1,1',3,3'-tetraethyl-benzimidazolyl-carbocyanine 

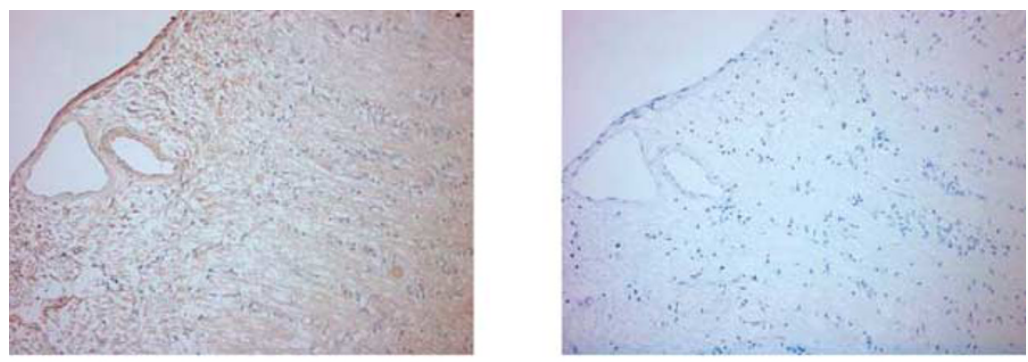

Human, control CML 1:2000, right: control staining
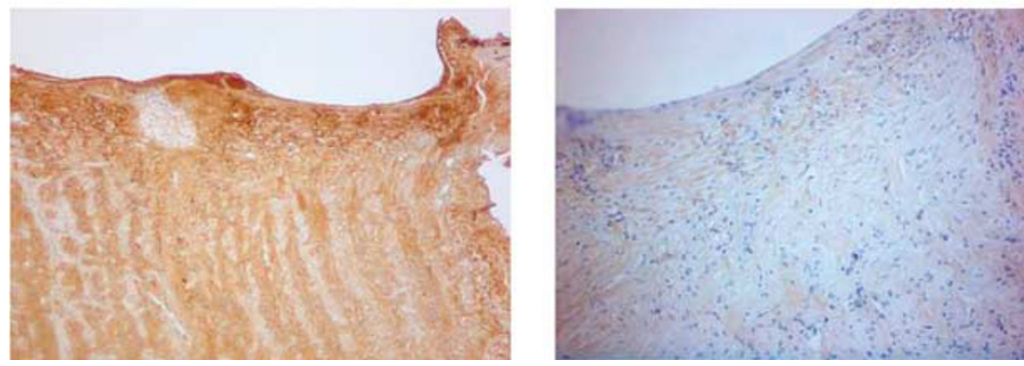

Human, glaucoma CML 1:2000, right: control staining

Figure 1 Staining of human eyes optic nerve heads showing an accumulation of $N(\varepsilon)$-(carboxymethyl) lysine (CML) (left pictures), with a greater presence in the retina section from a glaucomatous eye (bottom left).

iodide (JC-1). This dye was used in studies involving rat retinal cell line (E1A-NR3) and rat neuronal cell line (NG 108-15). Incubation of these cell lines with glyoxal, known to accelerate glycation and the formation of advanced glycation end products (AGEs, see below), an important pathological event in age-related ocular diseases, ${ }^{3}$ led to a decrease in intracellular $\mathrm{pH}$. This change was accompanied by morphological changes expressing signs of intracellular damage: membrane blebbing, and mitochondria and intracellular organelles gathering around the nucleus. At $1 \mathrm{~h}$ after glyoxal incubation, there was breakdown of the mitochondrial transmembrane potential (indicated by JC-1), mitochondrial swelling, followed by a nuclear fragmentation and apoptosis by $2 \mathrm{~h}$. We successfully demonstrated subsequently that the reduction of glyoxal-induced acidification by CA inhibitors protected a rat retinal cell line (E1A-NR3) from cell stress and apoptosis. $^{4}$

\section{AGEs}

The formation of AGEs is a key pathophysiological event in a range of important human diseases, and advanced glycation perceived as a possible modulator in important visual disorders. ${ }^{2}$ AGEs form via nonenzymatic condensation reactions between reducing sugars and $\varepsilon$-amino groups or $\mathrm{N}$-terminal groups, under conditions of relatively high blood glucose levels. This is also a normal process in every individual over the ages of 50 years. $^{2}$ AGE cross-links of proteins with sugars can affect protein structure and function, which can have pathological consequences, particularly given the formation of reactive intermediates making this process irreversible. Over time, the cross-linking can lead to 'AGEing' and mislocation of many protein types within cells. In the case of the retinal pigment epithelium (RPE), an additional metabolic load derives from the ingested photoreceptor discs: the discs also contain blue light-induced AGEs and advanced lipoxidation end products (ALEs). ${ }^{5,6}$ Furthermore, AGEs and ALEs lead to an increased production of free radicals. ${ }^{7}$

The presence of AGEs is an important physiological index in the retina of elderly patients. It has been possible to visualize the thickening of the basement membrane with AGEs and also the gradual loss of pericytes in retinal capillaries due to AGE load. ${ }^{8}$ In the present study, we can show AGEing of the nerve fibres, as indicated by an accumulation of a typical glycoxidation product, $N(\varepsilon)$-(carboxymethyl) lysine (CML) (Figure 1). Note that CML is greatly increased in the glaucoma subject than in the normal control.

The presence of AGEs inside the cell, and especially in axons, may affect axonal transport, as their by-products gather and block vesicles that are normally transported in axons, leading to the formation of vesicular 


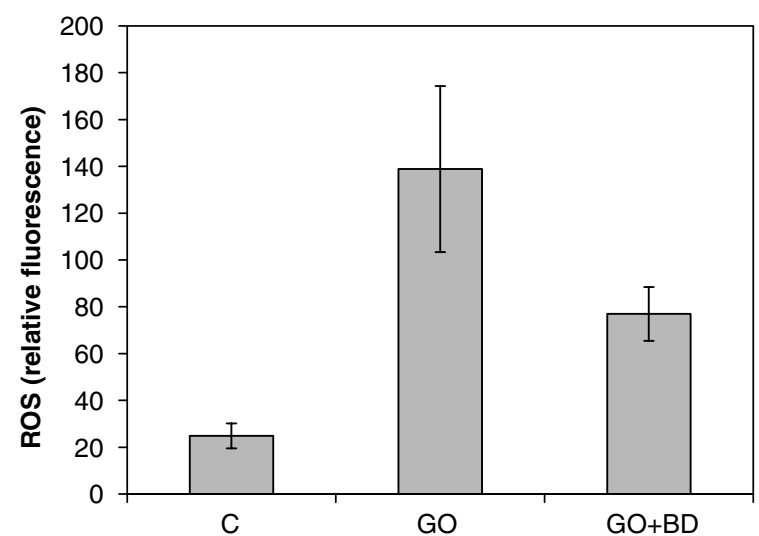

Figure 2 Inhibition of glyoxal-induced reactive oxygen species (ROS) production by brimonidine in the neuronal cell line NG 108-15. Cells were incubated for $24 \mathrm{~h}$ with medium (C), $0.6 \mathrm{~mm}$ glyoxal (GO), or $0.6 \mathrm{~mm}$ glyoxal $+2 \mu \mathrm{g} / \mathrm{ml}$ brimonidine (GO $+\mathrm{BD}$ ).

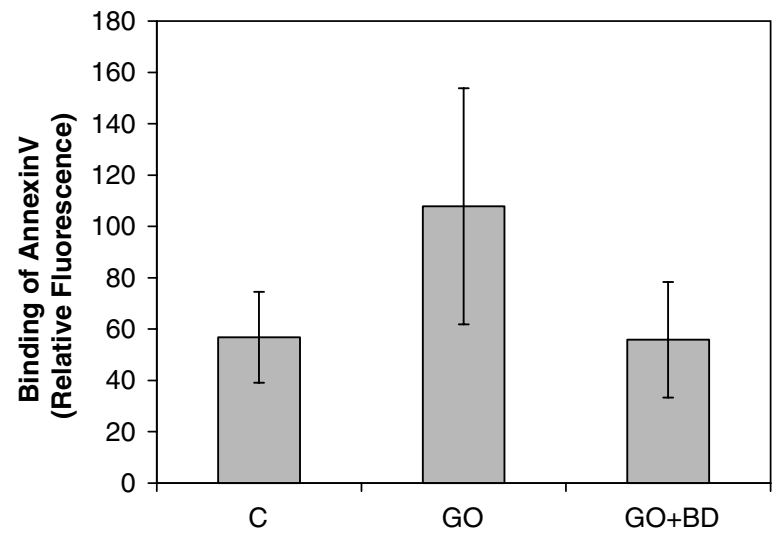

Figure 3 Inhibition of glyoxal-induced binding of annexin $\mathrm{V}$ by brimonidine in the neuronal cell line NG 108-15. Cells were incubated for $24 \mathrm{~h}$ with medium (C), $0.6 \mathrm{~mm}$ glyoxal (GO), or $0.6 \mathrm{~mm}$ glyoxal $+2 \mu \mathrm{g} / \mathrm{ml}$ brimonidine $(\mathrm{GO}+\mathrm{BD})$.

aggregates. ${ }^{9}$ In whole-mount ex vivo retina preparations, AGE-reactive intermediates (like glyoxal, which induces a time lapse AGEing, mimicking the long-term physiological AGE formation) induced rapid changes in the intracellular $\mathrm{pH}$ and mitochondria, leading to an impediment of axonal transport. ${ }^{10}$ The velocity of vesicles that are involved in axonal transport was also reduced.

\section{Potential neuroprotective effects of brimonidine and memantine}

The potential neuroprotective effects of brimonidine and memantine were studied in cultures of different cell

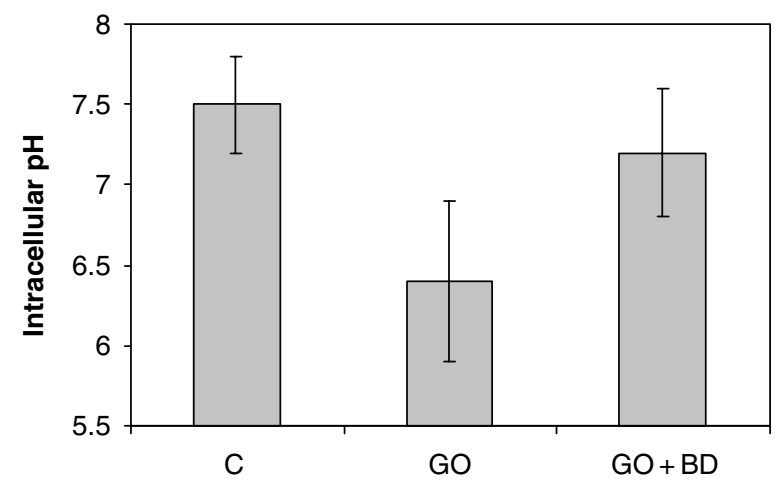

Figure 4 Inhibition of glyoxal-induced acidification of intracellular $\mathrm{pH}$ by brimonidine in retinal pigment epithelial cells (ARPE-19 cells; 5-h incubation with glyoxal (GO) and 24-h incubation with brimonidine (BD); concentration: glyoxal, $1 \mathrm{~mm}$; brimonidine, $0.05 \mathrm{mg} / \mathrm{ml}$ ). (Reproduced with permission from RH Funk.)

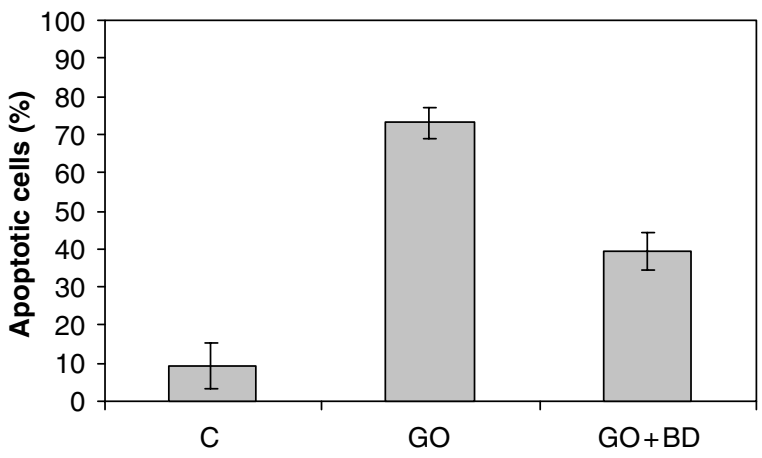

Figure 5 Inhibition of glyoxal-induced apoptosis by brimonidine in retinal pigment epithelial cells (ARPE-19 cells; 5-h incubation with glyoxal (GO) and 24-h incubation with brimonidine (BD); concentrations: glyoxal, $1 \mathrm{~mm}$; brimonidine, $0.05 \mathrm{mg} / \mathrm{ml}$ ). (Reproduced with permission from RH Funk.)

lines, where induced apoptosis was quantitated by flow cytometry. Brimonidine is a selective $\alpha-2$ adrenergic agonist, which has been shown to activate $\alpha-2$ adrenergic receptors in the retina and to have the potential to promote the survival and functionality of retinal cells. ${ }^{11}$ This agent was found to reduce both the acidification of intracellular $\mathrm{pH}$ and apoptosis induced by glyoxal (Figures 2 and 3; EM Kniep and RH Funk, private communication). Similar findings were obtained with apoptosis induced by radicals (reactive oxygen species, ROS) and rescue with brimonidine. The effects of brimonidine were seen not only in neuronal cells (Figures 2 and 3) but also in RPEs (Figures 4 and 5).

Memantine is an $N$-methyl-D-aspartate-sensitive glutamate receptor antagonist, which has been suggested to have neuroprotective effects by reducing 


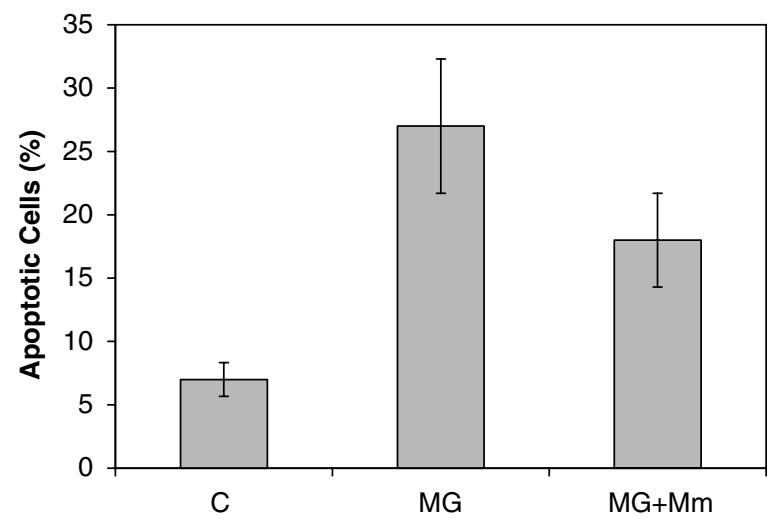

Figure 6 Inhibition of methylglyoxal-induced apoptosis by memantine in the retinal neuronal cell line R28. Cells were incubated for $24 \mathrm{~h}$ with medium $(\mathrm{C})$, for $5 \mathrm{~h}$ with $0.7 \mathrm{~mm}$ methylglyoxal, followed by $19 \mathrm{~h}$ with fresh medium (MG), or for $5 \mathrm{~h}$ with $0.7 \mathrm{~mm}$ methylglyoxal $+10 \mu \mathrm{g} / \mathrm{ml}$ memantine followed by $19 \mathrm{~h}$ with fresh medium $(\mathrm{MG}+\mathrm{Mm})$. Apoptotic cells were determined by the determination of cells with subdiploid DNA. (Reproduced with permission from RH Funk.)

glutamate-induced excitotoxicity. ${ }^{12}$ This drug was also found to inhibit apoptosis induced by glyoxal private communication.

\section{Conclusion}

Using the cellular systems described in this paper, it has been possible to demonstrate that intracellular $\mathrm{pH}$ changes can be used to monitor intracellular changes that precede and occur during apoptosis. The findings also show the potential significance of AGEs in the glaucomatous process, and the potential for brimonidine and memantine to rescue neuroretinal cells from AGE-induced retinal damage.

\section{References}

1 Reber F, Gersch U, Funk RH. Blockers of carbonic anhydrase can cause increase of retinal capillary diameter, decrease of extracellular and increase of intracellular $\mathrm{pH}$ in rat retinal organ culture. Graefes Arch Clin Exp Ophthalmol 2003; 241(2): 140-148.

2 Reber F, Kasper M, Siegner A, Kniep E, Seigel G, Funk RH. Alteration of the intracellular $\mathrm{pH}$ and apoptosis induction in a retinal cell line by the AGE-inducing agent glyoxal. Graefes Arch Clin Exp Ophthalmol 2002; 240(12): 1022-1032.

3 Stitt AW. Advanced glycation: an important pathological event in diabetic and age related ocular disease. $\mathrm{Br} \mathrm{J}$ Ophthalmol 2001; 85(6): 746-753.

4 Kniep EM, Roehlecke C, Özkucur N, Steinberg A, Reber F, Knels L. et al. Inhibition of apoptosis and reduction of intracellular $\mathrm{pH}$ decrease in retinal neural cell cultures by a blocker of carbonic anhydrase. Invest Ophthalmol Vis Sci 2006; 47(3): 1185-1192.

5 Shaban H, Richter C. A2E and blue light in the retina: the paradigm of age-related macular degeneration. Biol Chem 2002; 383(3-4): 537-545.

6 Sparrow JR, Zhou J, Cai B. DNA is a target of the photodynamic effects elicited in A2E-laden RPE by blue-light illumination. Invest Ophthalmol Vis Sci 2003; 44(5): 2245-2251.

7 Bonnefont-Rousselot D. Glucose and reactive oxygen species. Curr Opin Clin Nutr Metab Care 2002; 5: 561-568.

8 Stitt AW. Advanced glycation: an important pathological event in diabetic and age related ocular disease. $\mathrm{Br} \mathrm{J}$ Ophthalmol 2001; 85(6): 746-753.

9 Reber F, Reber U, Funk RH. Intracellular changes in astrocytes and NG 108-15 neuroblastoma $X$ glioma cells induced by advanced glycation end products. J Neural Transm 2003; 110(10): 1103-1118.

10 Menke T, Gille G, Reber F, Janetzky B, Andler W, Funk RH et al. Coenzyme Q10 reduces the toxicity of rotenone in neuronal cultures by preserving the mitochondrial membrane potential. Biofactors 2003; 18(1-4): 65-72.

11 Wheeler L, WoldeMussie E, Lai R. Role of alpha-2 agonists in neuroprotection. Surv Ophthalmol 2003; 48(Suppl 1): S47-S51.

12 Lipton SA. Paradigm shift in neuroprotection by NMDA receptor blockade: memantine and beyond. Nat Rev Drug Discov 2006; 5(2): 160-170. 